anthropologists, epidemiologists, and clinical psychiatrists might contribute. Co-ordination is essential, and might best be provided by a systems analyst or other person whose specific concern is the nature of the system itself. Even if full understanding is ultimately achieved many fully developed psychiatric disorders will probably be beyond effective treatment. Research will therefore need to be directed towards early ascertainment of the vulnerable and devising prophylactic regimens which might be more akin to educational programmes than medical treatments.

1 Shepherd, M., Comprehensive Psychiatry, 1971, 12, 302. 45, 105 .

3 Jones, H. G., Bulletin of the British Psychological Society, 1971, 24, 279.

4 British Medical fournal, 1971, 4, 68.

\section{Holiday Cholera}

With the approach of the annual holiday migration from these islands to the warm south, especially to southern Europe and North Africa, we again face the risk of cholera being imported into Britain. El Tor vibrios have in the last 10 years spread from Sulawesi (formerly Celebes) across Asia and Africa and are now encroaching on the continent of Europe. It is sometimes thought that because these vibrios are different from the classical cholera vibrios they do not produce the classical clinical picture of cholera. This is not true. Untreated patients with cholera due to El Tor vibrios may die from dehydration as surely as those with the classical type of vibrio. But no one should die from cholera. It is one of the most dramatic and rewarding diseases to treat.

The diarrhoea of cholera is characteristically painless and without fever. The tissues are not invaded by organisms or toxin, and until symptoms of dehydration occur the patient feels well. All that is needed is rapid and adequate rehydration. A patient comatose and apparently moribund can within an hour or two be sitting up in bed saying that he feels fine. An adult patient in shock may take a litre of fluid intravenously in 10 minutes. Once dehydration has been corrected, and this can be assessed by return of skin turgor and a good pulse, fluid replacement must continue to balance the output of fluid in the stools. Intermittent hydration and dehydration is dangerous and may be associated with renal failure. Even adults when severely affected can become dangerously dehydrated within a few. hours; in children the danger is greater. Saline alone is not adequate as fluid replacement. Intravenous fluid must replace loss of bases and combat the acidosis. For this purpose a number of solutions are available, ${ }^{1}$ and Ringer-lactate (Hartmann's solution) is easily obtainable. Fluid replacement may continue by mouth, because provided the fluid contains about $20 \mathrm{~g}$ of glucose per litre it will be absorbed even from a gut putting out large volumes of stools. This may make considerable demands on the nurses' time, as the patient has to be kept drinking so that the intake of fluid does not fall below output. In no form of diarrhoealeast of all cholera-is there any case for withholding fluids to "dry them out" as is sometimes suggested.

A country with hygienic disposal of excreta and with a good water supply is unlikely to experience a serious epidemic of cholera, though the possibility of outbreaks must be taken seriously, ${ }^{2}$ and it is important to be prepared for adequate treatment of all cases and the surveillance of all excreters. Symptomless excreters of El Tor vibrios are important in the spread of the disease. For each case of cholera there may be several cases with mild symptoms, diagnosed perhaps as "gastroenteritis" or even a "touch of diarrrhoea." There may be many more symptomless excreters. El Tor cholera appears often to have spread by human contact and by food. It should no longer be considered as an exclusively water-borne disease. Anyone with diarrhoea returning from southern Europe or other endemic areas should be considered as possibly infected with vibrios, and specimens of faeces should be sent as quickly as possible to the nearest laboratory, which must be alerted to look for vibrios in the faeces.

Vaccination has little part to play in the control of cholera in Europe or even less developed countries. The protection from the vaccine is too short-lived. In Britain a programme of mass vaccination would be unnecessary, and in countries with poor sanitation and water supply it is, as always, a question of priorities. But anyone travelling in an endemic area may well be advised to receive immunization against cholera for his personal protection. If it is undertaken, it should be preferably with two injections spaced at least 10 days apart. Intradermal injections are not recommended. ${ }^{3}$ Vaccines, which are usually prepared from classical strains of cholera and contain a mixture of the two serotypes, Inaba and Ogawa, will give protection against $\mathrm{El}$ Tor vibrios because they are antigenically the same. But the important thing for the traveller abroad is for him to know how the disease is spread and to take proper hygienic precautions with food and water. This is more troublesome than a "shot" in the arm but more efficacious, particularly for campers and caravanners.

The insistence on a valid certificate of immunization against cholera for travellers returning to this country serves no purpose. It does not even remove the possibility that the holder is a symptomless excreter of vibrios. Some countries, including the U.S.A., no longer insist on the production of certificates of immunization against cholera from those abroad. It is time we followed suit.

1 W.H.O. Public Health Papcrs, 1970, No. 40.

3 McBean, A. M., e: al., Lancet, 1972, 1, 527.

\section{Phototherapy in Neonatal Jaundice}

Phototherapy for the prevention and treatment of hyperbilirubinaemia in the newborn is being increasingly used, but its place in management is still controversial. Its mode of action, limitations, and possible hazards have been recently reviewed ${ }^{1-4}$ and were also the main topic of a symposium on bilirubin metabolism in the newborn. ${ }^{5}$

Phototherapy probably acts by oxidizing bilirubin, and it may also cause hepatic excretion of unconjugated bilirubin. ${ }^{6}$ It can prevent hyperbilirubinaemia in premature infants, ${ }^{78}$ but anxiety about the effects of the photodegradation products of biliribin and ignorance of its long-term sequelae have made paediatricians hesitate to use this form of 
therapy. Their hesitation is reinforced by the finding of general growth retardation and a head circumference of more than two standard deviations below the mean in six of 23 infants with a low birth weight (median age 44 weeks) who had been treated with phototherapy. There were similar findings in only one of 23 control infants (median age 47 weeks). ${ }^{9}$ The outcome of a prolonged follow-up of a larger series $^{10}$ should therefore be awaited before prophylactic phototherapy is advocated in infants with a low birth weight.

Another uncertainty is what concentration of bilirubin in the serum causes neurological damage. Though kernicterus has been shown to occur in severely asphyxiated or anoxic infants with maximum serum bilirubin concentrations of 9.4-15.6 mg/100 ml11 and of $18 \mathrm{mg} / 100 \mathrm{ml}, 12$ and retarded development at eight months was found in a poorly controlled series of infants with serum bilirubin concentrations of $16 \mathrm{mg} / 100 \mathrm{ml}$ or even less, ${ }^{13}$ much evidence suggests that in the absence of hypoxia, ${ }^{14}$ hypothermia, ${ }^{15}$ acidosis, ${ }^{16}$ and low serum albumin level ${ }^{17}$ a serum bilirubin concentration of $20 \mathrm{mg} / 100 \mathrm{ml}$ or less has no effect on subsequent I.Q.18-21 B. Wood and his colleagues ${ }^{18}$ found that the developmental assessment at one year, uncorrected for prematurity, was related to the severity of jaundice but that the I.Q. of the same infants when aged 6 was not. G. B. Odell and his colleagues ${ }^{22}$ reached somewhat similar conclusions, but made the important observation that in 32 jaundiced neonates assessed at the age of 4-7 years there was a highly significant relationship between the serum protein saturation index and abnormal cognitive findings. Such reports also support the view that routine phototherapy of premature infants, who on the above criteria have a $1 \%$ risk of requiring exchange transfusion, ${ }^{23}$ should await the outcome of adequate follow-up studies.

Phototherapy has not been very effective in controlling rapid rises in serum bilirubin, as in rhesus isoimmunization, ${ }^{24}$ but two recent reports ${ }^{25} 26$ indicate that it may be useful in A B O blood-group incompatibility. T. R. C. Sisson and colleagues ${ }^{25}$ found in a study of 35 infants (14 weighing less than $2.5 \mathrm{~kg}$ ), divided into a control (16) and a treated (19) group (matched for gestation, sex, weight, diagnosis, general health and diet), that in infants of all weights significantly lower serum bilirubin concentrations were achieved with phototherapy started when the serum bilirubin was $9.5 \mathrm{mg} / 100 \mathrm{ml}$ or more and continued until it fell below $8.5 \mathrm{mg} / 100 \mathrm{ml}$. There were no untoward effects. Five infants in the control group needed an exchange transfusion because of serum bilirubin concentrations of 16 or $18 \mathrm{mg} /$ $100 \mathrm{ml}$. E. Kaplan and colleagues, ${ }^{26}$ reviewing their experience in treating 29 cases of A B O incompatibility, concluded that it was often a mild disorder requiring no active treatment but that phototherapy was valuable when an early rise in serum bilirubin occurred and when it could be controlled within 24 hours. When the bilirubin continues to rise during this period they suggest that exchange transfusion is probably advisable.

The effective alternatives to phototherapy carry some risk. Exchange transfusion, still the mainstay in the management of hyperbilirubinaemia, has an appreciable morbidity and a mortality of $5-10 \% .{ }^{27} 28$ Phenobarbitone and other enzyme inducers can lower serum bilirubin concentrations, but their action is far from specific and subtle adverse effects may become apparent only with long-term evaluation. ${ }^{29}$ Orotic acid, a metabolic precursor of uridine diphosphate glucuronic acid (UDPGA), the glucuronide donor in bilirubin conjugation, has been given to both premature and full-term infants to lower serum bilirubin concentrations, but with conflicting results. ${ }^{30-31}$ The exciting report ${ }^{32}$ that agar lowers serum bilirubin concentrations in full-term infants by interrupting the enterohepatic circulation of bilirubin has yet to be shown to apply to infants at risk from hyperbilirubinaemia.

1 Behrman, R. E., and Hsia, D. Y. Y., Fournal of Pediatrics, 1969, 75, 718. 2 Lancet, 1970, 1, 825.

3 British Medical fournal, 1970, 2, 5.

Schmid, R., New England fournal of Medicine, 1971, 285, 520.

5 Bilirubin Metabolism in the Newborn, ed. D. Bergsma and D. Y. Y. Hsia. Baltimore, Williams \& Wilkins, 1970 .

- Ostrow, J. D., Fournal of Clinical Investigation, 1971, 50, 707.

7 Cremer, R. J., Perryman, P. W., and Richards, D. H., Lancet, 1958, 1,

8 Iucey, J. F., in Bilirubin Metabolism in the Newborn, ed. D. Bergsma and D. Y. Y. Hsia, p. 63. Baltimore, Williams \& Wilkins, 1970.

- Hodgman, J. E., and Teberg, A., in Bilirubin Metabolism in the Newborn, ed. D. Bergsma and D. Y. Y. Hsia, p. 75. Baltimore, Williams \& Wilkins, 1970

10 Warren, C. B. M., and Broughton, P. M. G., British Medical fournal, $1970,11,299$.

11 Gartner, L. M., Snyder, R. N., Chabon, R. S., and Bernstein, J., Pediatrics, 1970, 45, 906

12 Ackerman, B. D., Dyer, G. Y., and Leydorf, M. M., Pediatrics, 1970, 45,918 .

13 Boggs, T. R., Hardy, J. B., and Frazier, T. M., fournal of Pediatrics, 1967, $1,553$.

14 Lucey, J. F., Hibbard, E., Behrman, R. E., Esquivel de Gallardo, F. O., and Windle, W. F., Experimental Neurology, 1964, 9, 43.

15 Stern, L., and Doray, B. E., Proceedings of the 12 th International Congress of Pediatrics, Mexico City, Abstract No. 464, 1968.
.

16 Diamond, I., and Schmid, R., Fournal of Clinical Investigation, 1966, 45,

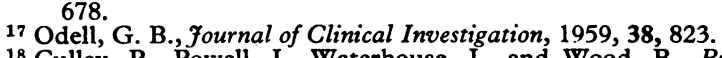

18 Culley, P., Powell, J., Waterhouse, J., and Wood, B., British Medical Fournal, 1970, 3, 383.

19 Johnston, W. H., et al., Pediatrics, 1967, 39, 88.

20 Holmes, G. E., Miller, J. B., and Smith, E. E., American fournal of Diseases of Children, 1968, 116, 37.

21 Stewart, R. R., Walker, W., and Savage, R. D., Developmental Medicine and Child Neurology, $1970,12,16$.

22 Odell, G. B., Storey, G. N. B., and Rosenberg, L. A., fournal of Pediatrics, $1970,76,12$.

28 Davies, P. A., Lancet, 1969, 2, 273.

24 Sisson, T. R. C., et al., Pediatric Research, 1969, 3, 380.

25 Sisson, T. R. C., Kendall, N., Glanser, S. C., Knutson, S., and Bunyaviroch, R. C., Kendall, N., Glanser, S. C., Kn

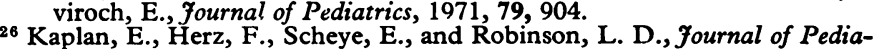
trics, $1971,79,91 \dot{1}$.

27 Kitchen, W. H., Australian Paediatric fournal, 1970, 6, 30.

28 Wilson, J. T., Pediatrics, 1969, 43, 324.

2 Matsuda, I., and Shirehata, T., Tohoku fournal of Experimental Medicine, $1966,90,133$.

${ }^{30}$ Gray, D. W. G., and Mowat, A. P., Archives of Disease in Childhood, 1971, 46, 123.

${ }^{31}$ Schwarze, R., Kintzel, H. W., and Hinkel, G. K., Acta Paediatrica Scandinavica, 1971, 60, 705.

s2 Poland, R. L., and Odell, G. B., New England Fournal of Medicine, 1971, 284,1 .

\section{A Career Structure for Cancer Research}

One of the main developments reported by the Imperial Cancer Research Fund ${ }^{1}$ is the establishment under Professor G. Hamilton Fairley at St. Bartholomew's Hospital of an extramural unit of medical oncology for research into the clinical aspects and treatment of the lymphomas and leukaemias. This development is significant in its own right, but it also has a wider importance, as the Fund's chairman, Professor E. F. Scowen, points out.

At present clinical cancer research lacks a career structure and tends to depend on a series of doctors and scientists undertaking research during their progress to other posts in medicine or science. To make full use of people and their ideas the possibility of full training in both laboratory and clinical methods must be available. In addition, "There must be a career structure in which workers can develop and mature if the first-class brain is to be attracted and main- 